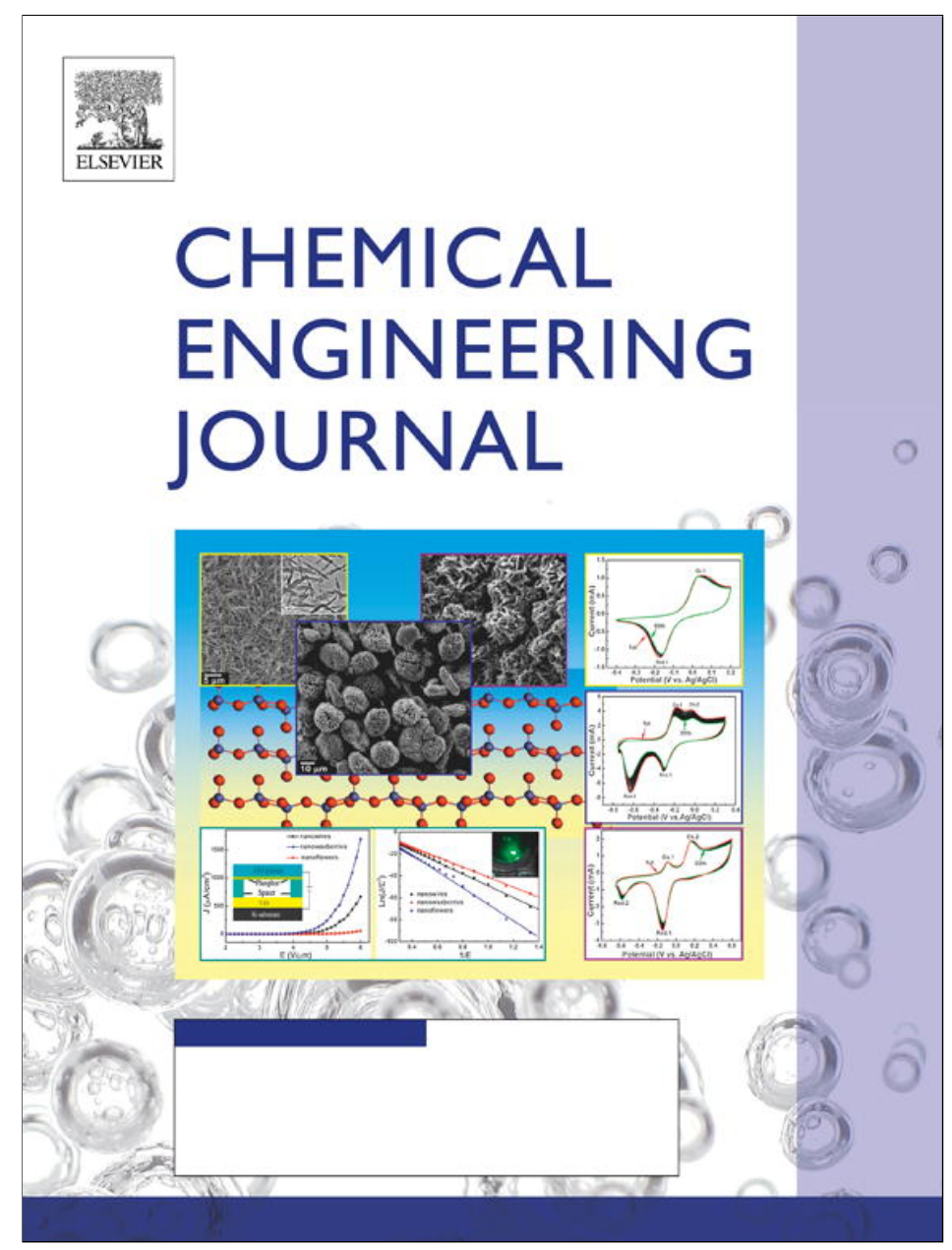

(This is a sample cover image for this issue. The actual cover is not yet available at this time.)

This article appeared in a journal published by Elsevier. The attached copy is furnished to the author for internal non-commercial research and education use, including for instruction at the authors institution and sharing with colleagues.

Other uses, including reproduction and distribution, or selling or licensing copies, or posting to personal, institutional or third party websites are prohibited.

In most cases authors are permitted to post their version of the article (e.g. in Word or Tex form) to their personal website or institutional repository. Authors requiring further information regarding Elsevier's archiving and manuscript policies are encouraged to visit: 


\title{
Synthesis of amidoximated polyacrylonitrile fibers and its application for sorption of aqueous uranyl ions under continuous flow
}

\author{
Nesrin Horzum ${ }^{\mathrm{a}}$, Talal Shahwan ${ }^{\mathrm{b}}$, Onur Parlak ${ }^{\mathrm{c}}$, Mustafa M. Demir ${ }^{\mathrm{a}, \mathrm{c}, *}$ \\ ${ }^{a}$ Department of Chemistry, Izmir Institute of Technology, 35430 İzmir, Turkey \\ ${ }^{\mathrm{b}}$ Department of Chemistry, Birzeit University, Ramallah, Palestine \\ ${ }^{\mathrm{c}}$ Materials Science and Engineering Program, Izmir Institute of Technology, 35430 Izmir, Turkey
}

\section{H I G H L I G H T S}

- Submicron diameter PAN fibers were successfully prepared by electrospinning.

- PAN fiber mat was found to be promising in sorption of $\mathrm{U}(\mathrm{VI})$ ions by column method.

- The surface of PAN fibers were postfunctionalized by amidoximation reaction.

- The surface modification remarkably enhanced U(VI) sorption capacity of PAN fibers.

\section{A R T I C L E I N F O}

\section{Article history:}

Received 2 August 2012

Received in revised form 21 September 2012

Accepted 21 September 2012

Available online 11 October 2012

\section{Keywords:}

Amidoximation

Desorption

Electrospinning

Sorption

Polyacrylonitrile

Uranyl ions

\section{G R A P H I C A L A B S T R A C T}
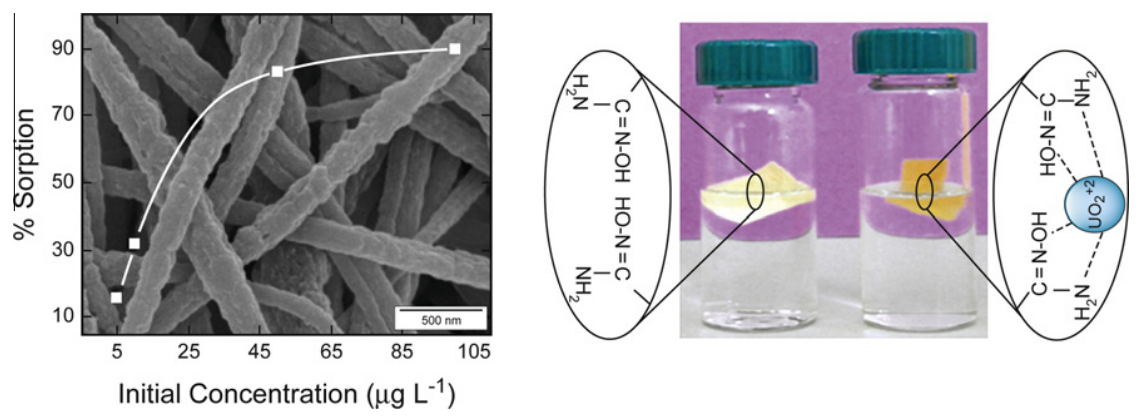

\begin{abstract}
A B S T R A C T
This study reports a feasible method for the removal of radioactive $\mathrm{U}(\mathrm{VI})$ ions from aqueous systems via column sorption under continuous flow. Electrospun polyacrylonitrile (PAN) fibers were used as sorbent materials in a homemade minicolumn. The nitrile groups on the fibers' surface were modified to amidoxime groups using hydroxylamine hydrochloride. Surface modification was observed to enhance the sorption capacity of PAN fibers toward uranium ions by more than 4-fold by virtue of the chelating ability of the amidoxime groups. The experiments investigated the effect of $\mathrm{pH}$, initial concentration, and repetitive loading on the sorption properties of amidoximated PAN fibers. Based on the overall results, the surfacemodified fibers seem to be a suitable potential sorbent material for applications in environmental cleanup, particularly for nuclear plants.
\end{abstract}

(c) 2012 Elsevier B.V. All rights reserved.

\section{Introduction}

Uranium is the heaviest naturally occurring radionuclide and has various harmful fouling effects in the environment. There are hundreds of uranium species, which account for $5 \%$ of all known

\footnotetext{
* Corresponding author at: Department of Chemistry, İzmir Institute of Technology, 35430 Izmir, Turkey. Tel.: +90 2327507511.

E-mail address: mdemir@iyte.edu.tr (M.M. Demir).
}

minerals [1]. This element is present in most rocks, soil, surface water, and groundwater in the order of a few parts per million. It is also discharged into the environment from many anthropogenic activities such as mining, military applications, production and use of phosphate fertilizers, combustion from coal and other fuels, and nuclear power facilities. The increasing usage of nuclear reactors for large-scale energy production leads to radioactive contamination; hence, research concerning the separation of $\mathrm{U}(\mathrm{VI})$ ions from water has become a critical environmental issue in the last decade [2-4]. 
There are two commonly used methods to remove $\mathrm{U}(\mathrm{VI})$ ions from solutions: (i) sequestration using organic compounds and (ii) fixation on surfaces of sorbent materials. The former involves the covalent interaction of uranyl ions with specific organic compounds until the ions are no longer radioactive [5]. However, use of this method requires reconsideration as radioactivity cannot be eliminated by chemical bonding. In the latter method, the ions are fixed onto the surface of a heterogeneous material through sorption. While the concentration of uranyl ions decreases in solution, it is enriched on the surface of the sorbent material.

The sorption of $\mathrm{U}(\mathrm{VI})$ ions can be achieved by various forms of natural and synthetic adsorbents, given in Table 1 . Several works related to uranium sorption onto naturally occurring clay minerals and soil fractions have been performed. Hudson et al. [6] examined vermiculate and hydrobiotite, and Sylwester et al. [7] examined silica, alumina, and montmorillonite as sorbents. Both studies investigated the $\mathrm{pH}$ dependence of uranyl oxo-cation $\left(\mathrm{UO}_{2}^{2+}\right)$ sorption and determined the local structure around the sorbed uranium atom. Kowal-Fouchard et al. [8] illuminated the surface complexation of uranyl ions and montmorillonite sorption sites. Kilincarslan and Akyil [9] studied uranium sorption on clinoptilolite zeolite surfaces and determined optimum conditions such as $\mathrm{pH}$, initial concentration, contact time, and temperature. The sorption behavior of uranium on sodium aluminosilicate solid phases was investigated by Addai-Mensah et al. [10] Greathouse and Cygan [11] concluded that siloxane groups of beidellite, montmorillonite, and pyrophyllite were responsible for uranyl sorption. Donat et al. [12] combined biomass and clay mineral to prepare an Ulva sp. sepiolite composite sorbent, and Khani [13] carried out optimization of uranium removal by a Padina sp. algal biosorbent.

To improve the sorption capacity of sorbents, many attempts have been made for chemical modification of sorbent surfaces using functional groups such as amidoxime [3,14,15], imidazole [16], and metal oxides $[4,17,18]$, which possess chelating abilities toward $\mathrm{U}(\mathrm{VI})$ ions. As commonly used sorbents are in powder form, their utilization as a filter material is not convenient due to the difficulty in the isolation of the solid from the solution medium following the sorption stage. Therefore, additional treatments might be needed, such as the coating of these sorbents onto a supporting surface, to efficiently use them for uranium removal. Zou et al. [19] modified natural zeolite surfaces using manganese oxide and tested uranium(VI) sorption performance with a fixed bed ionexchange column. The same authors reported the usage of manganese oxide-coated sand as a sorbent for the removal of uranyl ions in batch processing. Attention has recently been paid to

Table 1

Summary of sorption system suggested for uranium.

\begin{tabular}{|c|c|c|c|}
\hline Sorbents & Size & $\begin{array}{l}\text { Types of } \\
\text { sorption }\end{array}$ & References \\
\hline Streptomyces and chlorella cells & - & Column & [36] \\
\hline Polyethylene hollow fiber & $380 \mu \mathrm{m}$ & Column & [14] \\
\hline Montmorillonite & $<2 \mu \mathrm{m}$ & Batch & {$[7,8,11,37]$} \\
\hline Vermiculite and hydrobiotite & $<45 \mu \mathrm{m}$ & Batch & {$[6]$} \\
\hline Silica, alumina & $0.48 \mu \mathrm{m}$ & Batch & {$[7,10]$} \\
\hline $\begin{array}{l}\text { Amidoximated poly(acrylonitrile/ } \\
\mathrm{N} \text {-vinylimidazole) }\end{array}$ & $\begin{array}{l}4,5 \mathrm{~mm} \text { in } \\
\text { length }\end{array}$ & Batch & [3] \\
\hline Clinoptilolite zeolite & $<74 \mu \mathrm{m}$ & Batch & [9] \\
\hline $\begin{array}{l}\text { Hydrogels based on PEG and } \\
\text { methacrylic acid }\end{array}$ & - & Batch & [2] \\
\hline Ulva sp.-Sepiolite & $<125 \mu \mathrm{m}$ & Batch & [12] \\
\hline Manganese oxide coated zeolite & $60-200 \mu \mathrm{m}$ & Column & [18] \\
\hline Manganese oxide coated sand & $670-990 \mu \mathrm{m}$ & Batch & [38] \\
\hline Padina sp. algae biomass & $1.0-1.25 \mathrm{~mm}$ & Batch & [13] \\
\hline Titanium dioxide & $4-240 \mathrm{~nm}$ & Batch & [17] \\
\hline Iron oxide & $<15 \mathrm{~nm}$ & Batch & [4] \\
\hline
\end{tabular}

amidoxime chelating adsorbent in removing heavy toxic metals and/or selective recovering of precious metals. Takeda et al. [14] proposed a fixed bed adsorption unit containing amidoximemodified commercial polyethylene hollow fiber for the recovery of uranium from seawater. Pekel and Guven [3] studied uranyl ion uptake by amidoximated poly(acrylonitrile/N-vinylimidazole) complexing sorbents. It was reported that uranyl ion adsorption was achieved via the complexation abilities of the vinylimidazole and amidoxime groups. However, colloidal hydrogels as a filter medium are not favorable due to their lack of mechanical integrity accompanied by difficulty in the separation of the solid phase from aqueous media.

Electrospun fibrous materials are emerging as suitable alternatives to conventional sorbents due to their structural advantages conveyed by the nanosized diameter of the constituent fibers [15,20-25]. A high surface area-to-volume ratio (which leads to high sorption capacity), porosity, and mechanical integrity are the benefits of electrospun fibers. The fibers also serve as substrates for functional groups upon surface modification [26,27]. They can thus be potentially used for sorption and desorption of metal ions. Based on this, it seems reasonable to investigate the sorption efficiency of amidoxime-modified electrospun fiber for the removal of radioactive and chemically toxic $\mathrm{U}(\mathrm{VI})$ ions from aqueous systems. The surface-modified electrospun fibers used in this work have large surface areas and porosity as well as mechanical integrity, which are desirable properties in filtration applications. This makes such fibers superior in terms of sorption capability as compared to many of the powdered sorbents and colloidal hydrogels reported in earlier works. The sorption study described herein was designed to survey the characteristics of amidoximated polyacrylonitrile (PAN) fibers and to test their properties as a sorbent for $\mathrm{U}(\mathrm{VI})$ ions from synthetic solutions via a column system. Column-type continuous-flow sorption has an advantage over batch-type sorption as the rate of sorption depends on the concentration of solute in the solution being treated. In column treatment, the filter material is continuously in contact with fresh solution. By virtue of column sorption, the concentration in the solution changes very slowly; however, in batch sorption, the concentration of the solute decreases much more rapidly and thereby reduces the effectiveness of the sorbent. Compared to batch sorption, column sorption is more convenient in industrial applications due to its simplicity, the fact that it does not require any additional processes such as filtration or centrifugation, and its ability to provide a higher residence time. Many applications of filtering processes involve the removal of undesirable species under continuous flow of the solution. For example, in agricultural irrigation pipes, the filtering material is placed on a cross-section of the pipes such that it is normal to the flux direction of solution, and as such the mechanical resistance to the continuous flow becomes the main requirement for filtering material. In this sense, electrospun fiber mat may be a promising candidate for such applications [28].

\section{Experimental section}

\subsection{Materials}

Acrylonitrile (AN) and benzoyl peroxide (BPO) were provided by Fluka Chemical Company. For the surface modification of PAN fibers, hydroxylamine hydrochloride $\left(\mathrm{H}_{3} \mathrm{NO} \cdot \mathrm{HCl}\right)$ and sodium hydroxide $(\mathrm{NaOH})$ were supplied by Sigma-Aldrich and Riedel-de Haen Chemicals, respectively. N,N-dimethylformamide (DMF) (Sigma-Aldrich) was used as an electrospinning solvent and uranylacetate dihydrate $\left(\mathrm{UO}_{2}\left(\mathrm{CH}_{3} \mathrm{COO}\right)_{2} \cdot 2 \mathrm{H}_{2} \mathrm{O}\right.$; Merck) was used as a sorbate. Sodium bicarbonate $\left(\mathrm{NaHCO}_{3}\right.$; Fluka), ammonium 
citrate $\left(\mathrm{C}_{6} \mathrm{H}_{17} \mathrm{~N}_{3} \mathrm{O}_{7}\right.$; Sigma), and ethylenediaminetetraacetic acid $\left(\mathrm{C}_{10} \mathrm{H}_{16} \mathrm{~N}_{2} \mathrm{O}_{8}\right.$; Riedel-de Haen) were used as desorbing eluents. All chemicals were of reagent grade and ultrapure water (18.2 M $\Omega$ ) was used throughout the study.

\subsection{Instrumentation and software}

Electrospun fibers were analyzed by scanning electron microscope (SEM; Philips XL-30S FEG, Eindhoven, the Netherlands). ImageJ $1.43 \mathrm{u}$ software was used for the determination of fiber diameter from SEM micrographs. In each trial, 100 test fibers were measured and the average fiber diameter (AFD) and its standard deviation were determined. Energy dispersive X-ray (EDX) analysis was performed using an FEI XL30 W instrument equipped with an Apollo X Silicon Drift detector. Atomic distribution of the surface of the sorbents was obtained from randomly selected points.

The amidoximation reaction and uranyl sorption were investigated via Fourier transform infrared radiation (FT-IR) spectroscopy. FT-IR measurements of the samples before and after the amidoximation reaction as well as of uranyl sorbed-fibers were performed with a PerkinElmer Spectrum 100 FT-IR Spectrometer (Waltham, USA) with a PIKE MIRacle Single Reflection Horizontal ATR Accessory. The amount of uranium ions was determined using an inductively coupled plasma (ICP) spectrometer (Agilent 7500ce Series, Japan). The ICP-MS operation parameters are given in Table S1 of Appendix A. Standard solutions of 5.0, 10.0, 25.0, 50.0, 100.0, 200.0, 500.0, and $1000.0 \mu \mathrm{g} \mathrm{L}^{-1}$ concentrations were prepared by appropriate dilution of $10.0 \mathrm{mg} \mathrm{L}^{-1} \mathrm{U}(\mathrm{VI})$ stock solution to the required volume. All samples and standard solutions were acidified through the addition of the proper amount of concentrated $\mathrm{HNO}_{3}$ to produce $1.0 \%(\mathrm{v} / \mathrm{v})$ acid in the final solution. The percentage of uranium sorption was calculated using Eq. (1), where $C_{i}$ is the initial and $C_{f}$ is the final concentration in the solution.

\%Sorption $=\frac{C_{i}-C_{f}}{C_{i}} \times 100$

The speciation analysis of uranium-containing ions at various pH values was performed using Visual MINTEQ software.

\subsection{Polymerization of acrylonitrile}

Polymerization of acrylonitrile was carried out at $60^{\circ} \mathrm{C}$ using benzoyl peroxide as an initiator. AN $(0.076 \mathrm{~mol})$ and BPO $(0.0076 \mathrm{~mol})$ were mixed in a sealed glass tube after sonication for $15 \mathrm{~min}$. Three cycles of a freeze-thaw process were applied prior to polymerization. The glass tube containing the AN and BPO was placed into a preheated bath at $60^{\circ} \mathrm{C}$; the polymerization was performed under an $\mathrm{N}_{2}$ atmosphere and it was stopped after the desired time by quenching to room temperature. The resulting product was dissolved in DMF and purified in methanol under continuous mixing for $3 \mathrm{~h}$, and then filtrated under vacuum. After filtration, the polyacrylonitrile were dried under vacuum for $6 \mathrm{~h}$ at $40{ }^{\circ} \mathrm{C}$.

The viscosity average molecular weight of the synthesized polymer was determined by using a Petrotest capillary viscosimeter (Dahlewitz, Germany) placed in a water bath thermostatically controlled at $25^{\circ} \mathrm{C}$. The polymerization products were dissolved in DMF at concentrations ranging from $1.3 \mathrm{~g} \mathrm{~L}^{-1}$ to $3.9 \mathrm{~g} \mathrm{~L}^{-1}$. Calculations were made using the Mark-Houwink equation $[\eta]=K M_{v}^{\alpha}$, where $K$ and $\alpha$ are the specific constants for a given polymer and vary for the used solvent system and temperature [29]. The $K$ and $\alpha$ of PAN are equal to $0.21 \mathrm{~cm}^{3} \mathrm{~g}^{-1}$ and 2.20 , respectively. The polymer used in the experiment has viscosity molecular weight $\left(M_{v}\right)$ in the range of $180 \mathrm{~kg} \mathrm{~mol}^{-1}$.

To determine the number average molecular weight $\left(M_{n}\right)$ of the polymer, a $400 \mathrm{MHz}$ NMR system (Varian VnmrJ, Palo Alto, USA) was employed; $M_{n}$ was calculated as $14 \mathrm{~kg} \mathrm{~mol}^{-1}$. The ratio of protons on the end-groups to the protons on the polymer backbone was determined by integration of ${ }^{1} \mathrm{H}$ NMR signals.

\subsection{Electrospinning of polyacrylonitrile}

The electrospinning solution of the synthesized PAN was prepared by dissolving the polymer ( $4 \mathrm{wt} \%$ ) in DMF. The PAN solution was placed in a $20 \mathrm{~mL}$ syringe fitted with a metallic needle of $0.2 \mathrm{~mm}$ in inner diameter. The syringe was fixed horizontally on the microinfusion pump (LION WZ-50C6), and the electrode of the high-voltage power supply (Gamma High Voltage Research, Ormond Beach, USA) was attached to the metal needle tip. The flow rate of the polymer solution was $2 \mathrm{~mL} \mathrm{~h}^{-1}$, voltage of $15 \mathrm{kV}$ was applied to the needle, and the distance between the needle and the collector was $5 \mathrm{~cm}$. The electrospinning process was performed at room temperature and the resulting fiber mat was held in vacuum at $50{ }^{\circ} \mathrm{C}$ overnight to remove any residual solvent.

\subsection{Surface treatment of PAN fibers}

The hydrophilic character of the electrospun PAN fiber was increased by converting the nitrile groups of AN to amidoxime groups. For the amidoximation reaction, a recipe given in the literature was followed [30]. Hydroxylamine hydrochloride $(0.375 \mathrm{~g})$, sodium hydroxide $(0.375 \mathrm{~g})$, and $25.0 \mathrm{mg}$ of PAN nanofiber mats were added to a $50 \mathrm{~mL}$ beaker and continuously stirred for 2 days at room temperature. After surface reaction, the nanofiber mats were washed several times with distilled water to remove the remaining salts and were dried in a vacuum oven at $60^{\circ} \mathrm{C}$.

\subsection{Sorption studies}

Aqueous $\mathrm{U}(\mathrm{VI})$ solutions were prepared by dissolving a proper amount of $\left(\mathrm{UO}_{2}\left(\mathrm{CH}_{3} \mathrm{COO}\right)_{2} \cdot 2 \mathrm{H}_{2} \mathrm{O}\right)$ in ultrapure water. Column studies were carried out in order to show the applicability of amidoximated PAN fiber sorbent in the continuous removal of uranyl from aqueous solution. A homemade microcolumn system involving Teflon tubing with an internal diameter of $1.5 \mathrm{~mm}$ and $50 \mathrm{~mm}$ of height was employed in the experiments. $30 \mathrm{~mm}$ of the tubing height was filled with amidoximated PAN fiber sorbents. Cylindrically shaped small sponge pieces were squeezed into both ends of the tube such that the amidoximated PAN fibers were sandwiched and the back-pressure of the continuous flow was prevented. The schematic representation of the experimental setup of the column study is illustrated in Fig. 1. The U(VI) solution flowed downward at a flow rate of $0.15 \mathrm{~mL} \mathrm{~min}^{-1}$ with use of a peristaltic pump. The samples of effluent were collected regularly at $3 \mathrm{~mL}$ volume fractions at different initial concentrations and solution $\mathrm{pH}$ values.

The effect of $\mathrm{pH}$ on the extent of sorption was conducted after adjusting the initial $\mathrm{pH}$ levels of the solutions to 3.0, 4.0, and 8.0 using $0.01 \mathrm{M}, 0.1 \mathrm{M}$, and $1.0 \mathrm{M}$ of $\mathrm{HNO}_{3}$ and $\mathrm{NH}_{3}$ solutions. In each experiment, $45.0 \mathrm{~mL}$ of $\mathrm{U}(\mathrm{VI})$ solution was circulated.

The experiments investigating the effect of initial concentration were performed at 5.0, 10.0, 50.0, and $100.0 \mu^{g^{-1}}$ concentrations. In each study, $3.0 \mathrm{~mL}$ of $\mathrm{U}(\mathrm{VI})$ solution (adjusted to $\mathrm{pH} 4.0$ ) was circulated.

In order to study the effect of repetitive loading, a series of experiments were carried out. In each experiment, $3 \mathrm{~mL}$ aliquots of fresh $\mathrm{U}(\mathrm{VI})$ solutions having initial concentrations of 50.0 and $100.0 \mu \mathrm{g} \mathrm{g}^{-1}$ were loaded 14 times. The experiments were further continued using $100.0 \mu \mathrm{g} \mathrm{g}^{-1}$ solution and the sorbent was exposed to 80 successive doses of $3.0 \mathrm{~mL}$ of solution.

For desorption experiments, the uranyl ion-loaded sorbent was treated with $3.0 \mathrm{~mL}$ aliquots of $0.5 \mathrm{M} \mathrm{NaHCO}_{3}, 0.5 \mathrm{M} \mathrm{C}_{6} \mathrm{H}_{17} \mathrm{~N}_{3} \mathrm{O}_{7}$, and $0.1 \mathrm{M}$ EDTA. Consecutive sorption-desorption cycles were 


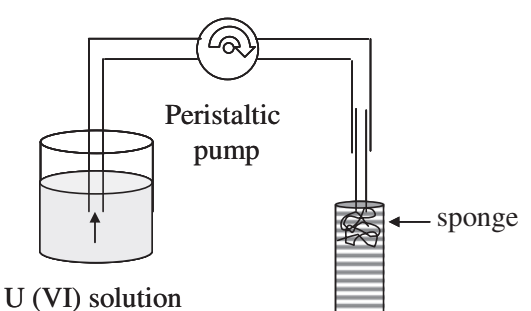

PAN-oxime fiber layers

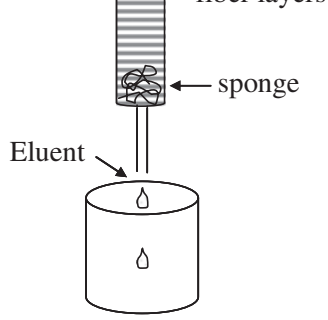

Fig. 1. Schematic representation of experimental setup of column experiment.

performed to study the reusability of the amidoximated PAN fiber sorbent. The eluted solutions were then analyzed for possible sorbed and released $\mathrm{U}(\mathrm{VI})$ ions.

\section{Results and discussion}

The main aim of this work was to design a sorbent material as well as an easily practicable column system for removal of contaminating uranium(VI) ions from aqueous solutions. We thus prepared submicron-diameter PAN fibers using the electrospinning method. The surface of the fibers was modified by amidoxime groups and the sorption ability of both the modified and unmodified fibers was studied.

\subsection{Fabrication of PAN fibers}

PAN was synthesized through free radical bulk polymerization at $60{ }^{\circ} \mathrm{C}$ using $\mathrm{BPO}$ as an initiator. Fig. S1 in Appendix A shows the NMR spectra of acrylonitrile and polyacrylonitrile. The number average and viscosity molecular weights are 14 and $180 \mathrm{~kg} \mathrm{~mol}^{-1}$, respectively. PAN fibers were obtained through electrospinning of PAN/DMF solution at different concentrations. The concentration was fixed to $4 \mathrm{wt} \%$ in terms of solid content. A series of trials were carried out to obtain bead-free and uniform morphology at different potential differences and flow rates. The electrospinning process (the fiber fabrication) was optimized at a potential difference of $3 \mathrm{kV} \mathrm{cm}^{-1}$ and a flow rate of $2 \mathrm{~mL} \mathrm{~h}^{-1}$.

\subsection{Surface treatment of PAN fibers}

The surface modification of PAN fibers was performed by a wet chemical process. Scheme 1 shows the proposed reaction mechanism of hydroxylamine hydrochloride with the PAN nitrile group in a neutralized medium. The nitrile groups on the surface of PAN fibers react with $\mathrm{H}_{2} \mathrm{NOH}$ at room temperature. The hydroxylamine undergoes nucleophilic addition to the fibers' surface and a subsequent arrangement to carboximidamide. Eventually, the surface of the fibers is functionalized for chelating uranyl cations. The conversion of the PAN nitrile group into an amidoxime group $\left(C_{n}\right)$ was estimated using the following equation [31]:

$C_{n}=\frac{W_{1}-W_{0}}{W_{0}} \times \frac{M_{0}}{M_{1}} \times 100$

Here, $W_{0}$ and $W_{1}$ are the weights of the PAN nanofiber mat before and after the amidoximation reaction, respectively. $M_{1}$ is the molecular weight of hydroxylamine $\left(33 \mathrm{~g} \mathrm{~mol}^{-1}\right)$ and $M_{0}$ is the molecular weight of the acrylonitrile repeat unit $\left(53 \mathrm{~g} \mathrm{~mol}^{-1}\right)$. The conversion of the PAN nitrile group into an amidoxime group was calculated as $30 \%$. The resulting fibers were soft and light yellow, and this observation is compatible with previously reported results [15].

Fig. 2 shows the FT-IR spectra of PAN fiber and amidoximated PAN fiber, as well as the fiber after sorption of uranyl ions. A characteristic band of nitrile groups at $2260 \mathrm{~cm}^{-1}$ is present on the surface of all types of fibers. In the FT-IR spectrum of amidoximated PAN fibers, there are additional bands arising from the newly formed $\mathrm{H}_{2} \mathrm{~N}-\mathrm{C}=\mathrm{N}-\mathrm{OH}$ groups that support the successful surface modification. The reaction of hydroxylamine with nitrile groups leads to the formation of $\mathrm{C}=\mathrm{N}$ groups characterized by the band at $1665 \mathrm{~cm}^{-1}$. The broad band at $3000-3700 \mathrm{~cm}^{-1}$ can be attributed to $\mathrm{H}$-bondings of $\mathrm{NH}_{2}$ and $\mathrm{O}-\mathrm{H}$ in the amidoxime structure (panel a). Upon the sorption of $\mathrm{UO}_{2}^{2+}$ ions, a shift was observed in the stretching band of $\mathrm{C}-\mathrm{N}$ from $1218 \mathrm{~cm}^{-1}$ to $1248 \mathrm{~cm}^{-1}$ (panel b). The implication of this shift for the sorption mechanism is discussed in the last section.

Fig. 3 presents SEM micrographs and diameter distributions of PAN, amidoxime-modified PAN, and the modified fibers after uranyl sorption. Panel a of Fig. 3 shows PAN fibers prepared from $4 \mathrm{wt} \%$ PAN/DMF solution. The AFD was $122 \pm 39 \mathrm{~nm}$. The fibers appear to possess a homogeneous morphology with some surface roughness. Upon the amidoximation process, the AFD was slightly larger $(127 \pm 24 \mathrm{~nm})$ than that of untreated PAN fibers (panel b). The sorption of uranyl ions by the amidoximated PAN fibers

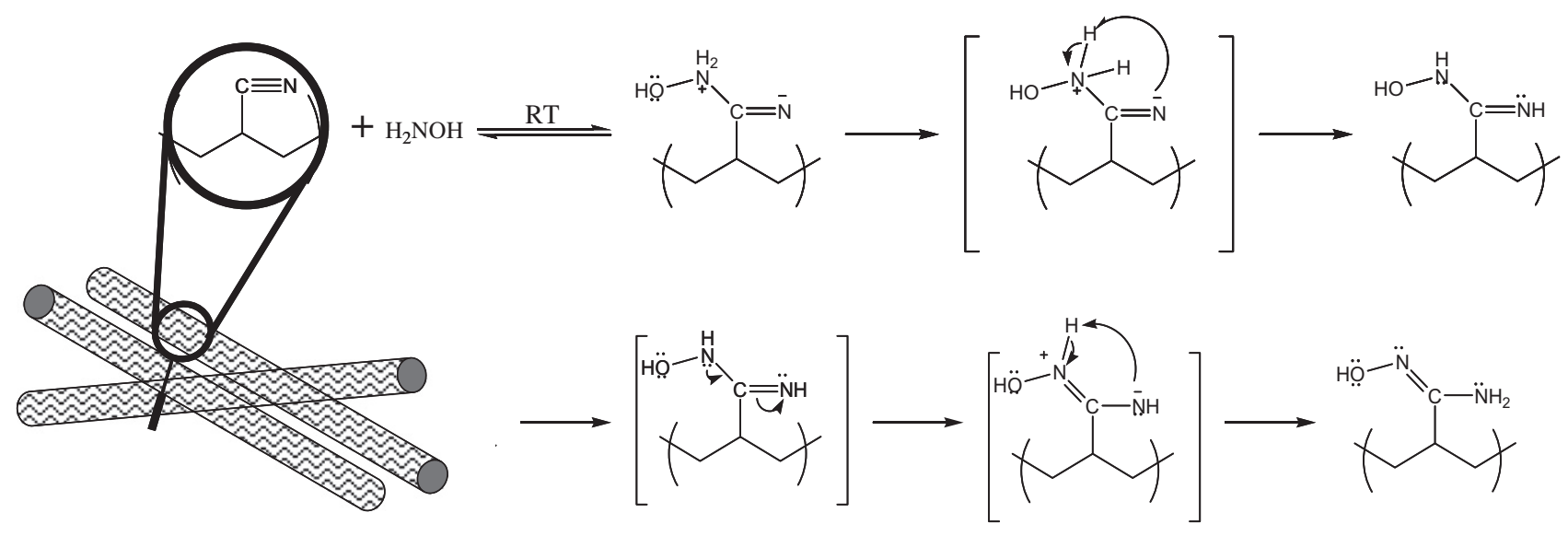

Scheme 1. The conversion of nitrile groups to amidoxime groups in PAN fiber. 


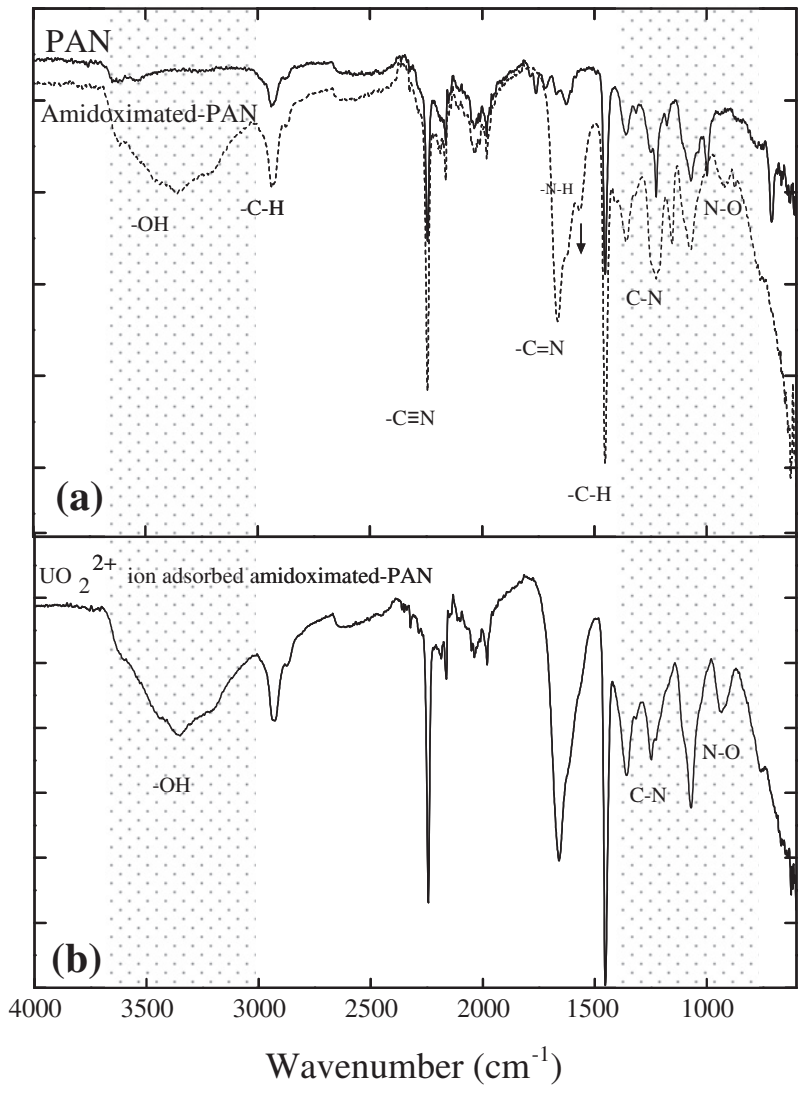

Fig. 2. FT-IR spectra of (a) PAN and amidoximated PAN fibers and (b) uranyl ionadsorbed amidoximated PAN fibers.

seemed to render the fiber thicker and undulatory, as the AFD for the fibers increased to $132 \pm 26 \mathrm{~nm}$ (panel c). No serious deterioration of the surface texture or roughness was observed after the sorption process, and the morphology and the integrity of the fibers were preserved. The elemental composition of amidoximated PAN fiber after uranyl ion sorption was elucidated using EDX analysis. Fig. 4 shows a typical EDX spectrum of uranyl ion-loaded fiber exposed to an initial concentration of $100 \mathrm{mg} \mathrm{L}^{-1}$. A high $\mathrm{U}(\mathrm{VI})$ initial concentration was selected due to the detection limit of EDX. The quantification is given in Table 2. C, N, and $\mathrm{O}$ signals originated from the polyacrylonitrile and the presence of a uranium signal indicated that uranium was fixed on the surface of the amidoximated PAN fiber. The atomic percentage of $U$ on the fiber surface was within the range of 0.50-1.09.

\subsection{Sorption studies}

The sorption capability of amidoxime-modified PAN fibers was compared with that of unmodified PAN fibers. The unmodified PAN fibers exhibited 19\% sorption; on the other hand, amidoximemodified PAN fibers showed nearly 4 times higher sorption capacity (81\%). It is worth noting that the sponge that was used in the experiments has no contribution to uranyl sorption. The surface modification also transformed the hydrophobic nitrile groups into hydrophilic amidoxime groups, and the sorption of uranyl ions increased due to the chelating ability of the amidoxime groups $[3,14,15]$.

\subsubsection{Effect of $\mathrm{pH}$}

The initial $\mathrm{pH}$ value of the solution is a significant parameter in uranium(VI) sorption. Fig. 5 shows the speciation diagram of $U(V I)$ as a function of $\mathrm{pH}$ (panel a) and the extent of sorption of $\mathrm{U}(\mathrm{VI})$ ions on amidoximated PAN fiber at different $\mathrm{pH}$ values (panel b). The percent $\mathrm{U}(\mathrm{VI})$ uptake increased as $\mathrm{pH}$ levels increased from 3.0 to 4.0. The amidoximated PAN fiber sorbent seemed to demonstrate maximum sorption at $\mathrm{pH} 4.0$. At this $\mathrm{pH}, \mathrm{UO}_{2}^{2+}$ ion is the main species (approximately $85 \%$ of the $\mathrm{U}(\mathrm{VI})$ ) among other chemical forms. Under lower $\mathrm{pH}$ values, uranium is still present in the form of free $\mathrm{UO}_{2}^{2+}$ ions; however, competitive sorption with protons occurs and ion-exchange interactions are favored [6,7]. Protonation can occur on the imino group of amidoxime ( $\mathrm{pKa}$ 5.95) [32], leading to a decrease in the chelating ability. For solutions adjusted at $\mathrm{pH}$ levels above 4.0, hydrated uranyl cations like $\mathrm{UO}_{2}(\mathrm{OH})^{+},\left[\left(\mathrm{UO}_{2}\right)_{3}(\mathrm{OH})_{5}\right]^{+}, \mathrm{UO}_{2}(\mathrm{OH})_{2},\left[\mathrm{UO}_{2}(\mathrm{OH})_{3}\right]^{-}$, and $\left[\mathrm{UO}_{2}(\mathrm{OH})_{4}\right]^{2-}$ seem to be dominant according to the speciation analysis. In high $\mathrm{pH}$ media, carbonate might also contribute as ligands in solutions open to the atmosphere. The change in the chemical form in terms of charge and number of hydroxyl ligands associated with possible steric limitations might be expected to decrease the extent of the fixation of $\mathrm{U}(\mathrm{VI})$ at higher $\mathrm{pH}$ values. The major species present in solution at $\mathrm{pH} 8.0$ is the neutral uranyl cation $\left(\mathrm{UO}_{2}(\mathrm{OH})_{2}\right)$, which is less liable to complexation than the positively charged $\mathrm{U}(\mathrm{VI})$ species and is expected to result in a lower extent of sorption.

\subsubsection{Effect of initial concentration}

The effect of initial concentration on the extent of removal of uranyl ions by amidoximated PAN fiber was investigated. Throughout these experiments, a fixed amount of sorbent $(25.0 \mathrm{mg})$ was employed, and the initial concentration of the $\mathrm{U}(\mathrm{VI})$ solutions varied in the range of $5-100 \mu \mathrm{g} \mathrm{L}^{-1}$ at a fixed $\mathrm{pH}$ of 4.0. Fig. 6 displays uranyl ion sorption as a function of initial concentration. The amount of adsorbed uranyl ions increased with the increase of the initial uranyl ion concentration, and at an initial uranyl concentration of $100 \mu \mathrm{g} \mathrm{L}^{-1}$, the sorption approached the saturation plateau. The observed behavior is probably due to the decrease in the hydration effects of water, the increase of the entropy effects of ions in solution, and, consequently, a greater mobility of the uranyl ions as concentration is increased. In addition, when more $\mathrm{U}(\mathrm{VI})$ ions are present in the solution, a higher fraction of available active sites takes part in the sorption process [33]. This could be attributed to the associated limitation in the number of water molecules available for hydration of the exposed hydrophilic groups at the fiber surface.

\subsubsection{Repetitive usability}

To test the repetitive usability of the amidoximated PAN fiber sorbent, $3 \mathrm{~mL}$ portions of fresh $\mathrm{U}(\mathrm{VI})$ solution at the initial concentrations of $100 \mu \mathrm{g} \mathrm{L}^{-1}$ and $50 \mu \mathrm{g} \mathrm{L}^{-1}$ were exposed to fiber samples for 14 successive trials. The results are presented in Fig. 7. The amidoximated PAN fiber sorbent seems to be effective in removal of aqueous $\mathrm{U}(\mathrm{VI})$ ions even after 14 consecutive uses. In the initial trials, more uranyl ions appear to be removed at a higher initial concentration, which is in line with the results above. Nonetheless, at the initial $\mathrm{U}(\mathrm{VI})$ concentration of $100 \mu \mathrm{g} \mathrm{L} \mathrm{L}^{-1}$, the percent sorption seems to decrease gradually with more applications of the fiber. It is worth noting that the repetitive loading experiments continued for 80 trials before saturation of the sorbent was reached (see Fig. S2 in Appendix A). The results showed that more than $85 \%$ of the uranyl ions were sorbed after one use, and although sorption ability toward uranyl ions decreased steadily, $46 \%$ removal of uranyl ions could still be achieved even at the 80th trial of the same sorbent in the column. The most prominent consequence of this experiment is the high capacity of the sorbent under continuous flow.

The cumulative fixation of uranyl ions after dozens of trials is interesting. The first conclusion to be drawn from this behavior 

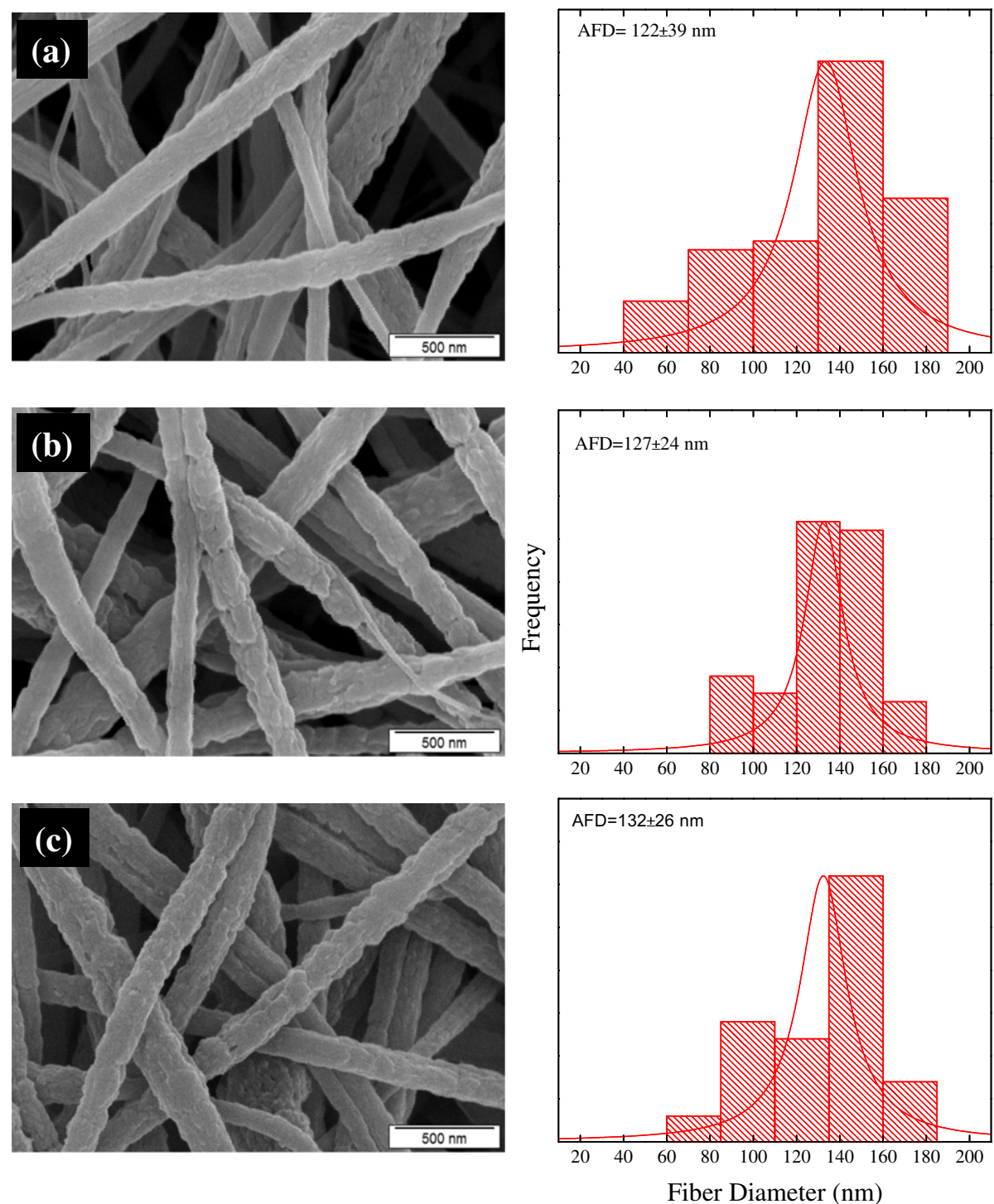

Fig. 3. Scanning electron micrographs and corresponding fiber diameter distributions of (a) PAN fibers, (b) amidoximated PAN fibers, and (c) amidoximated PAN fibers after uranyl ion sorption.

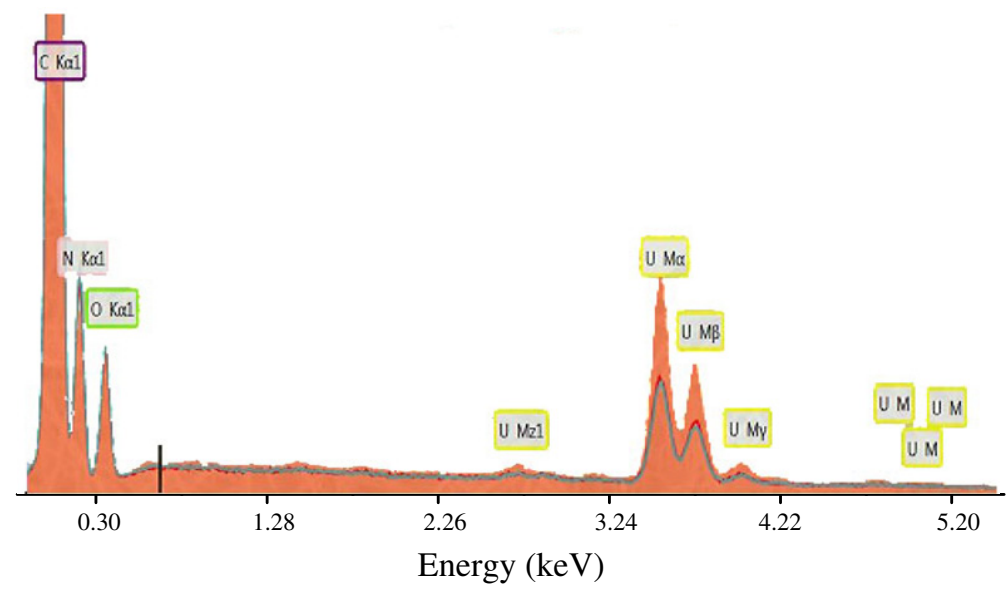

Fig. 4. EDX spectrum of amidoximated PAN fiber mat after uranyl ion sorption at $\mathrm{pH} 4$

is that the fibers possess a high density of sorption sites in comparison with the employed concentration of uranyl ions. The second conclusion relates to the apparent effectiveness of the hydration forces in solution. For ions with a high charge such as $\mathrm{U}(\mathrm{VI})$, the 
Table 2

The weight percentages and atomic percentages (in brackets) of $\mathrm{C}, \mathrm{N}, \mathrm{O}$, and $\mathrm{U}$ in amidoximated-PAN fiber after column sorption.

\begin{tabular}{lllll}
\hline Element & $\mathrm{C}$ & $\mathrm{N}$ & $\mathrm{O}$ & $\mathrm{U}$ \\
\hline Sampling area 1 & $58.69(67.83)$ & $26.19(25.95)$ & $6.60(5.72)$ & $8.52(0.50)$ \\
Sampling area 2 & $59.62(68.14)$ & $26.21(25.69)$ & $6.70(5.75)$ & $7.48(0.43)$ \\
Sampling area 3 & $55.62(70.27)$ & $20.39(22.09)$ & $6.87(6.55)$ & $17.06(1.09)$ \\
\hline
\end{tabular}

chemical potential is largely affected by the hydration forces in solution, especially in dilute solutions. As long as the chemical potential of the adsorbate on the surface is less than its chemical potential in solution, sorption proceeds spontaneously. When the ionic concentration is high, the ions become more mobile (i.e. their chemical potential increases) due to ionic repulsions, and as a result they can reach the surface and compete for sorption sites more readily. This seems to be achieved when fresh solution is fed into the column.

\subsubsection{Desorption tests}

The uranyl ion-loaded amidoximated PAN fiber sorbents were subsequently treated with different desorbing eluents. $\mathrm{NaHCO}_{3}$, EDTA, and ammonium citrate were employed as chelating agents for the release of uranyl ions and the regeneration of the sorbent. Fig. 8 shows the elution curves, which present almost similar behavior in each case. Most of the $\mathrm{U}(\mathrm{VI})$ ions were desorbed within the first $3.0 \mathrm{~mL}$ cycle, and the amounts of desorbed metal ions were almost unchanged. The desorption percentages of $\mathrm{U}(\mathrm{VI})$ were $80 \%$ for $0.5 \mathrm{M} \mathrm{NaHCO}_{3}, 45 \%$ for $0.5 \mathrm{M}$ ammonium citrate, and $34 \%$ for $0.1 \mathrm{M}$ EDTA. Therefore, $\mathrm{NaHCO}_{3}$ was selected as the desorbing eluent due to its relatively higher desorption yield. Uranium forms negatively charged or neutral carbonate complexes, and the adsorbed uranyl could be eluted from the sorbent using $\mathrm{NaHCO}_{3}$ through the addition of carbonate ions as ligands to uranyl complexes.

Fig. 9 displays the reusability of the fiber sorbent in five sorption/desorption cycles using $0.5 \mathrm{M} \mathrm{NaHCO}_{3}$. After five cycles, the efficiency of sorption decreased from $86.0 \%$ to $59.5 \%$ while the recovery of $\mathrm{U}(\mathrm{VI})$ decreased from $80.0 \%$ to $55.0 \%$. Therefore, $\mathrm{NaHCO}_{3}$ can regenerate the sorbent effectively, thus facilitating the reuse of this new fibrous material.

\subsubsection{Brief comments on sorption mechanism}

As mentioned previously, the amidoximated PAN fiber sorbent demonstrated maximum sorption at $\mathrm{pH}$ 4.0. The speciation analysis discussed previously suggests that, at this $\mathrm{pH}$, approximately $85 \%$ of the $\mathrm{U}(\mathrm{VI})$ exists in $\mathrm{UO}_{2}^{2+}$ chemical forms. From the sorbent side, as shown above based on FT-IR characterization, the surface

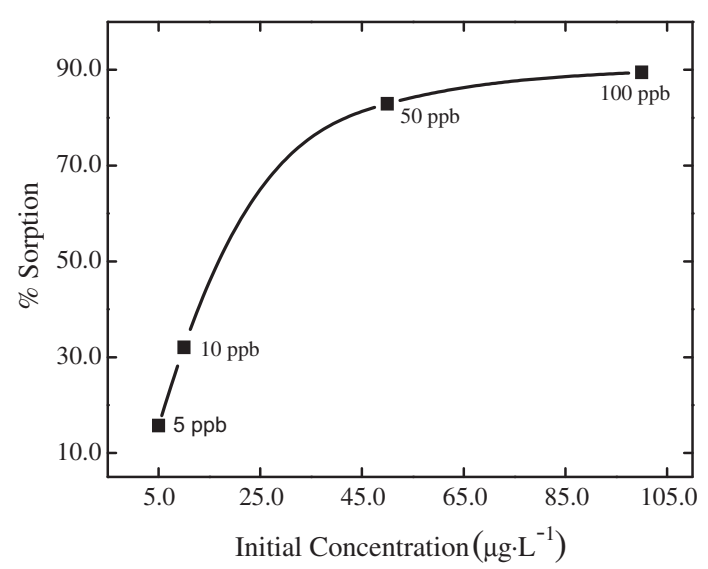

Fig. 6. Uranyl ion sorption at various initial concentrations. Reaction conditions: $3.0 \mathrm{~mL}$ sample volume, $0.15 \mathrm{~mL} \mathrm{~min}^{-1}$ flow rate, $25.0 \mathrm{mg}$ sorbent, $\mathrm{pH} 4.0$.

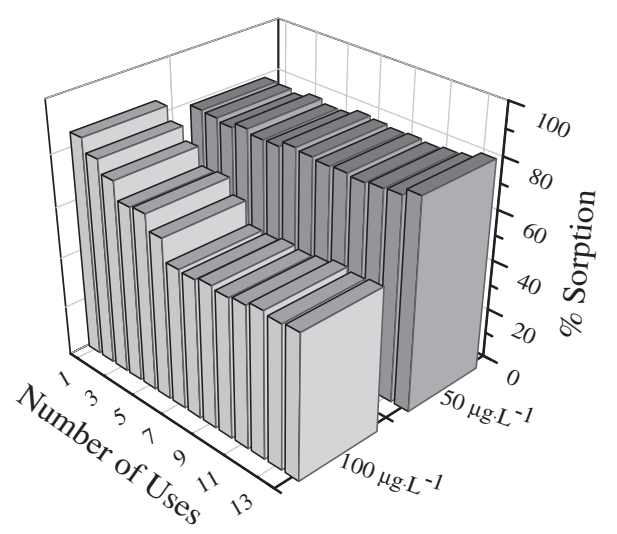

Fig. 7. Variation of percent sorption of uranyl ion with the number of repetitive usages of the same fiber sorbent at the initial $\mathrm{U}(\mathrm{VI})$ concentrations of $50 \mu \mathrm{g} \mathrm{L}^{-1}$ and $100 \mu \mathrm{g} \mathrm{L}^{-1}$. Reaction conditions: $3.0 \mathrm{~mL}$ sample volume, $0.15 \mathrm{~mL} \cdot \mathrm{min}^{-1}$ flow rate, $25.0 \mathrm{mg}$ sorbent, $\mathrm{pH} 4.0$.

of the functionalized fiber is dominated by hydroxyl, amine, and nitrile groups. In acidic media these groups would normally be expected to undergo protonation. Thus, at $\mathrm{pH} 4.0$, the chemical forms of the sorbent surface and the sorbate ions do not support an electrostatic hypothesis of sorption. The fixation of the $\mathrm{UO}_{2}^{2+}$ ions might therefore be expected to proceed via formation of surface complexes that possess a coordinative nature, with the lone pairs on $\mathrm{O}$ and $\mathrm{N}$ atoms in the surface groups playing the main role in interaction with the uranyl species.
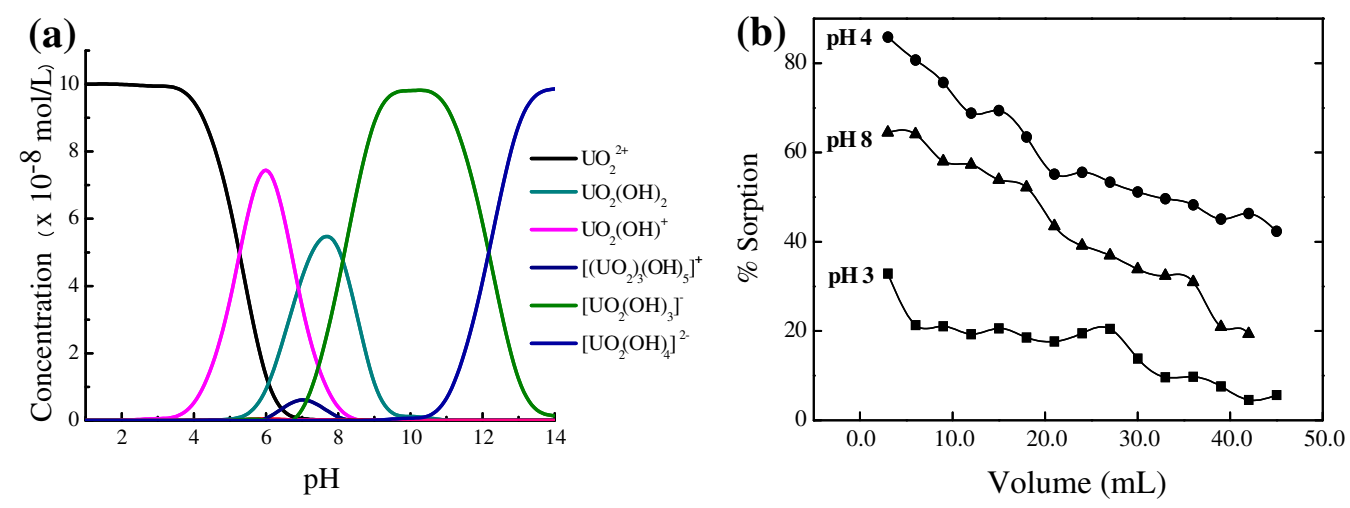

Fig. 5. (a) Speciation diagram of $\mathrm{U}(\mathrm{VI})$ and (b) microcolumn study of $\mathrm{U}(\mathrm{VI})$ at different $\mathrm{pH}$ values. Reaction conditions: initial $\mathrm{U}(\mathrm{VI})$ concentration of $100 \mu \mathrm{g} \mathrm{L}^{-1}, 0.15 \mathrm{~mL} \mathrm{~min}^{-1}$ flow rate, $25.0 \mathrm{mg}$ sorbent. 


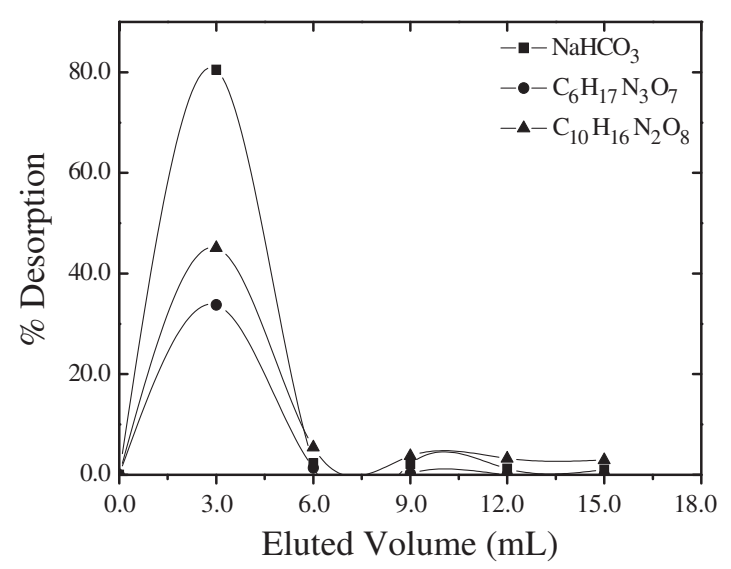

Fig. 8. Uranyl ion desorption as a function of eluted volume. Reaction conditions: initial $\mathrm{U}(\mathrm{VI})$ concentration of $100 \mu \mathrm{g} \mathrm{L}^{-1}, 0.15 \mathrm{~mL} \cdot \mathrm{min}^{-1}$ flow rate, $25.0 \mathrm{mg}$ sorbent.

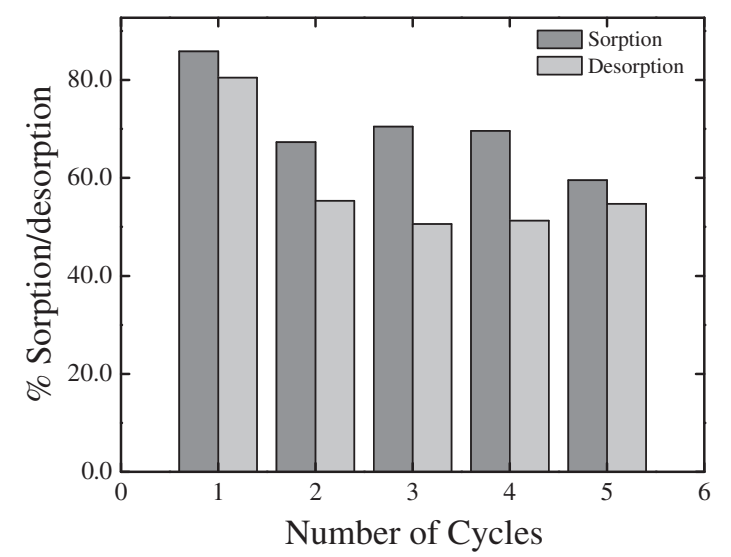

Fig. 9. Consecutive sorption/desorption cycles of amidoximated PAN fiber for $100 \mu \mathrm{g} \mathrm{L}{ }^{-1} \mathrm{U}(\mathrm{VI})$ solution using $0.5 \mathrm{M} \mathrm{NaHCO}_{3}$ as the desorbing agent.

The interaction of $\mathrm{UO}_{2}^{2+}$ ions with amidoximated PAN fibers is reflected in a blue shift in the stretching band of $\mathrm{C}-\mathrm{N}$ from $1218 \mathrm{~cm}^{-1}$ to $1248 \mathrm{~cm}^{-1}$, as mentioned above in Section 3.2. This result is compatible with previous works. For example, Pekel and Guven [3] observed a similar type of shift at the $\mathrm{C}-\mathrm{N}$ stretching

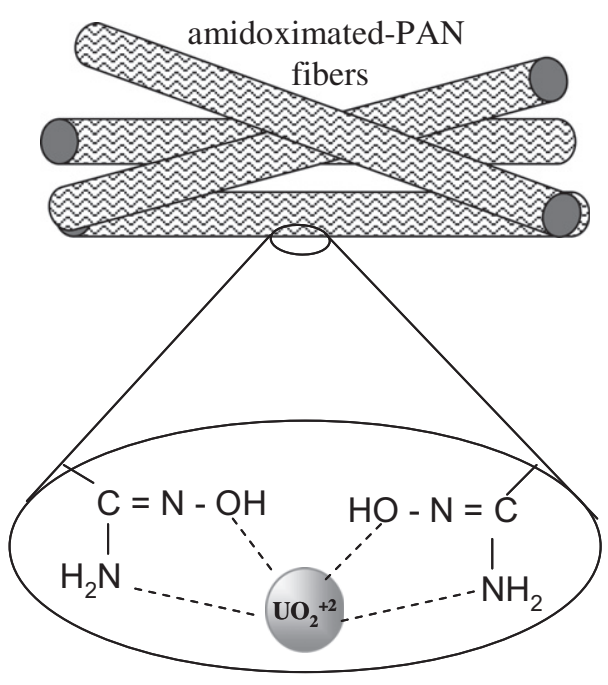

Scheme 2. Speculative binding mechanism. band for amidoximated poly(acrylonitrile/ $N$-vinylimidazole) complexing sorbent, which was taken as proof of the interaction of $\mathrm{UO}_{2}^{2+}$ ions with the vinylimidazole ring. It is proposed that the sorption of uranyl oxo-cations with amidoximated PAN fibers is achieved by virtue of the strong chelating ability of the amidoxime groups, which act as bidentate ligands. Based on the above discussion, a tentative binding mechanism is suggested in Scheme 2. This is in line with previously suggested chelation mechanisms. For example, Hirotsu et al. [34] reported that the sorption of uranium originated from ligand exchange between carbonate ions and amidoxime groups accompanied by deprotonation of the amidoxime groups. Similarly, Pekel et al. [35] proposed that the binding of the amidoxime group to $\mathrm{UO}_{2}^{2+}$ ions proceeded by replacement of protons by $\mathrm{UO}_{2}^{2+}$ ions.

More spectroscopic and structural investigations are required to make more precise and detailed comments on the sorption mechanism.

\section{Conclusions}

This study demonstrated that amidoximated PAN fibers produced by electrospinning are an effective sorbent for the removal of $\mathrm{U}(\mathrm{VI})$ from aqueous media via column-type operations. In the fabrication process, PAN fibers were first produced. A wet chemical process was then applied for surface modification of PAN fibers. The nitrile groups on the PAN fibers were converted to amidoxime groups using hydroxylamine hydrochloride in a neutralized medium. The surface-functionalized PAN fiber network provided higher metal-binding ability. The extent of $\mathrm{U}(\mathrm{VI})$ sorption on the fibers was found to depend on the $\mathrm{pH}$ of the medium and the initial concentration of the salt. The optimum $\mathrm{pH}$ for $\mathrm{U}(\mathrm{VI})$ sorption by amidoximated PAN fibers was found to be 4.0 , at which $\mathrm{UO}_{2}^{2+}$ ion is the main species. The adsorbed amount of $\mathrm{U}(\mathrm{VI})$ ions increased with an increase in initial $\mathrm{U}(\mathrm{VI})$ concentration. The ease and applicability of the process that we propose in filtration can offer a convenient method for the removal of $\mathrm{U}(\mathrm{VI})$ ions via a column system. Moreover, the amidoximated PAN fibrous filter material used in this study has high mechanical resistance, sorption ability, and efficient reusability, which are desired for filtration applications. Based on our preliminary results, this material is also capable of the uptake of various undesirable ions, such as $\mathrm{Fe}(\mathrm{III}), \mathrm{Cu}(\mathrm{II})$, and $\mathrm{Cd}(\mathrm{II})$, from aqueous solutions. A detailed study dealing with isotherms and sorption mechanisms is underway.

\section{Acknowledgements}

The authors acknowledge the Center of Material Research at IYTE and the Environmental Research Center for assistance in all measurements.

\section{Appendix A. Supplementary material}

Supplementary data associated with this article can be found, in the online version, at http://dx.doi.org/10.1016/j.cej.2012.09.114.

\section{References}

[1] M. Kalin, W.N. Wheeler, G. Meinrath, The removal of uranium from mining waste water using algal/microbial biomass, J. Environ. Radioact. 78 (2005) 151-177.

[2] G.A. Mun, Z.S. Nurkeeva, G.S. Irmukhametova, O. Guven, Synthesis, characterization and adsorption study of the uranyl ions by hydrogels based on polyethylene glycol and methacrylic acid copolymers 265 (2007) 379-384

[3] N. Pekel, O. Guven, Separation of uranyl ions with amidoximated poly(acrylonitrile/N - vinylimidazole) complexing sorbents, Colloid Surf. APhysicochem. Eng. Asp. 212 (2003) 155-161. 
[4] S. Sadeghi, H. Azhdari, H. Arabi, A.Z. Moghaddam, Surface modified magnetic $\mathrm{Fe}_{3} \mathrm{O}_{4}$ nanoparticles as a selective sorbent for solid phase extraction of uranyl ions from water samples, J. Hazard. Mater. 215 (2012) 208-216.

[5] P.L. Arnold, G.M. Jones, S.O. Odoh, G. Schreckenbach, N. Magnani, J.B. Love, Strongly coupled binuclear uranium-oxo complexes from uranyl oxo rearrangement and reductive silylation 4 (2012).

[6] E.A. Hudson, L.J. Terminello, B.E. Viani, M. Denecke, T. Reich, P.G. Allen, J.J. Bucher, D.K. Shuh, N.M. Edelstein, The structure of $\mathrm{U}^{6+}$ sorption complexes on vermiculite and hydrobiotite, Clay Clay Miner. 47 (1999) 439-457.

[7] E.R. Sylwester, E.A. Hudson, P.G. Allen, The structure of uranium (VI) sorption complexes on silica, alumina, and montmorillonite, Geochim. Cosmochim. Acta 64 (2000) 2431-2438.

[8] A. Kowal-Fouchard, R. Drot, E. Simoni, J.J. Ehrhardt, Use of spectroscopic techniques for uranium (VI)/montmorillonite interaction modeling, Environ. Sci. Technol. 38 (2004) 1399-1407.

[9] A. Kilincarslan, S. Akyil, Uranium adsorption characteristic and thermodynamic behavior of clinoptilolite zeolite, J. Radioanal. Nucl. Chem. 264 (2005) 541-548.

[10] J. Addai-Mensah, J. Li, M. Zbik, W.R. Wilmarth, Uranium sorption on solid aluminosilicate phases under caustic conditions, Sep. Sci. Technol. 40 (2005) 267-279.

[11] J.A. Greathouse, R.T. Cygan, Water structure and aqueous uranyl(VI) adsorption equilibria onto external surfaces of beidellite, montmorillonite, and pyrophyllite: results from molecular simulations, Environ. Sci. Technol. 40 (2006) 3865-3871.

[12] R. Donat, K. Esen, H. Cetisli, S. Aytas, Adsorption of uranium(VI) onto Ulva sp.sepiolite composite, J. Radioanal. Nucl. Chem. 279 (2009) 253-261.

[13] M.H. Khani, Statistical analysis and isotherm study of uranium biosorption by Padina sp. algae biomass, Environ. Sci. Pollut. Res. 18 (2011) 790-799.

[14] T. Takeda, K. Saito, K. Uezu, S. Furusaki, T. Sugo, J. Okamoto, Adsorption and elution in hollow-fiber-packed bed for recovery of uranium from seawater, Ind. Eng. Chem. Res. 30 (1991) 185-190.

[15] K. Saeed, S. Haider, T.J. Oh, S.Y. Park, Preparation of amidoxime-modified polyacrylonitrile (PAN-oxime) nanofibers and their applications to metal ions adsorption, J. Membr. Sci. 322 (2008) 400-405.

[16] N. Pekel, N. Sahiner, O. Guven, Development of new chelating hydrogels based on N-vinyl imidazole and acrylonitrile, Radiat. Phys. Chem. 59 (2000) 485491.

[17] M.J. Comarmond, T.E. Payne, J.J. Harrison, S. Thiruvoth, H.K. Wong, R.D. Aughterson, G.R. Lumpkin, K. Muller, H. Foerstendorf, Uranium sorption on various forms of titanium dioxide - influence of surface area, surface charge, and impurities, Environ. Sci. Technol. 45 (2011) 5536-5542.

[18] W.H. Zou, L. Zhao, R.P. Han, Removal of uranium (VI) by fixed bed ionexchange column using natural zeolite coated with manganese oxide, Chin. J. Chem. Eng. 17 (2009) 585-593.

[19] W.H. Zou, H.J. Bai, L. Zhao, K. Li, R.P. Han, Characterization and properties of zeolite as adsorbent for removal of uranium(VI) from solution in fixed bed column, J. Radioanal. Nucl. Chem. 288 (2011) 779-788.

[20] M.M. Demir, I. Yilgor, E. Yilgor, B. Erman, Electrospinning of polyurethane fibers, Polymer 43 (2002) 3303-3309.

[21] K. Desai, K. Kit, J.J. Li, P.M. Davidson, S. Zivanovic, H. Meyer, Nanofibrous chitosan non-wovens for filtration applications, Polymer 50 (2009) 36613669 .
[22] S. Haider, S.Y. Park, Preparation of the electrospun chitosan nanofibers and their applications to the adsorption of $\mathrm{Cu}(\mathrm{II})$ and $\mathrm{Pb}(\mathrm{II})$ ions from an aqueous solution, J. Membr. Sci. 328 (2009) 90-96.

[23] E. Klimov, V. Raman, R. Venkatesh, W. Heckmann, R. Stark, Designing nanofibers via electrospinning from aqueous colloidal dispersions: effect of cross-linking and template polymer, Macromolecules 43 (2010) 6152-6155.

[24] T. Ren, Y. Si, J.M. Yang, B. Ding, X.X. Yang, F. Hong, J.Y. Yu, Polyacrylonitrile/ polybenzoxazine-based $\mathrm{Fe}_{3} \mathrm{O}_{4} @$ carbon nanofibers: hierarchical porous structure and magnetic adsorption property, J. Mater. Chem. 22 (2012) 15919-15927.

[25] Y. Si, T. Ren, B. Ding, J.Y. Yu, G. Sun, Synthesis of mesoporous magnetic $\mathrm{Fe}_{3} \mathrm{O}_{4} @$ carbon nanofibers utilizing in situ polymerized polybenzoxazine for water purification, J. Mater. Chem. 22 (2012) 4619-4622.

[26] H. Dong, E. Fey, A. Gandelman, W.E. Jones, Synthesis and assembly of metal nanoparticles on electrospun poly(4-vinylpyridine) fibers and poly(4vinylpyridine) composite fibers, Chem. Mat. 18 (2006) 2008-2011.

[27] S. Agarwal, J.H. Wendorff, A. Greiner, Chemistry on electrospun polymeric nanofibers: merely routine chemistry or a real challenge?, Macromol Rapid. Commun. 31 (2010) 1317-1331.

[28] N. Horzum, E. Boyaci, A.E. Eroglu, T. Shahwan, M.M. Demir, Sorption efficiency of chitosan nanofibers toward metal ions at low concentrations, Biomacromolecules 11 (2010) 3301-3308.

[29] J.C. Seferis, Polymer Handbook, Wiley \& Sons, New York, 1999.

[30] N. Sahiner, N. Pekel, O. Guven, Radiation synthesis, characterization and amidoximation of $\mathrm{N}$-vinyl-2-pyrrolidone/acrylonitrile interpenetrating polymer networks, React. Funct. Polym. 39 (1999) 139-146.

[31] W.P. Lin, Y. Lu, H.M. Zeng, Studies of the preparation, structure, and properties of an acrylic chelating fiber containing amidoxime groups, J. Appl. Polym. Sci. 47 (1993) 45-52.

[32] L.N. Koikov, N.V. Alexeeva, E.A. Lisitza, E.S. Krichevsky, N.B. Grigoryev, A.V. Danilov, I.S. Severina, N.V. Pyatakova, V.G. Granik, Granik, Oximes amidoximes and hydroxamic acids as nitric oxide donors, Mendeleev Commun. (1998) 165-168.

[33] M.K. Sureshkumar, D. Das, M.B. Mallia, P.C. Gupta, Adsorption of uranium from aqueous solution using chitosan-tripolyphosphate (CTPP) beads, J. Hazard. Mater. 184 (2010) 65-72.

[34] T. Hirotsu, S. Katoh, K. Sugasaka, Adsorption Equilibrium of Uranium from Aqueous $\left[\mathrm{UO}_{2}\left(\mathrm{CO}_{3}\right)_{3}\right]^{4-}$ Solutions on a Polymer bearing Amidoxime Groups, 1986,pp. 1983-1986.

[35] N. Pekel, N. Sahiner, O. Guven, Thermodynamics of adsorption of uranyl ions onto amidoximated poly(acrylonitrile)/poly(N-vinyl 2-pyrrolidone) interpenetrating polymer networks, J. Polym. Sci. Pt. B - Polym. Phys. 42 (2004) 986-993.

[36] A. Nakajima, T. Horikoshi, T. Sakaguchi, Studies on the accumulation of heavymetal elements in biological-systems. 21. Recovery of uranium by immobilized microorganisms, Eur. J. Appl. Microbiol. 16 (1982) 88-91.

[37] J.P. McKinley, J.M. Zachara, S.C. Smith, G.D. Turner, The influence of uranyl hydrolysis and multiple site-binding reactions on adsorption of $\mathrm{U}(\mathrm{VI})$ to montmorillonite, Clay Clay Miner. 43 (1995) 586-598.

[38] W.H. Zou, L. Zhao, R.P. Han, Adsorption characteristics of uranyl ions by manganese oxide coated sand in batch mode, J. Radioanal. Nucl. Chem. 288 (2011) 239-249. 